\title{
EFFICACY OF INTRACORONAL BLEACHING USING NON THERMAL ATMOSPHERIC PRESSURE PLASMA AND ITS EFFECT ON PULP CHAMBER DENTIN. AN INVITRO STUDY
}

\author{
Heba Mahmoud Abdel Hamid* , Gihan Aly Abdel Rahman** , \\ Taheya Ahmed Moussa**, and Farouk Fahmy Elakshar ${ }^{* * *}$
}

\begin{abstract}
Aim: The aim of this study was to evaluate the efficacy of intracoronal bleaching using non thermal atmospheric pressure plasma and its effect on pulp chamber dentin structure.

Materials and methods: Two types of commercially available hydrogen peroxide bleaching systems were used in this study with a concentration of $32 \%$ (White smile $\mathrm{GmbH}$ ). Thirty eight single rooted premolars were collected. The teeth were sectioned in half longitudinally in a mesiodistal direction and specimens were prepared according to the testing method used. Specimens were stained with a prepared standardized coffee solution. The sectioned teeth were divided into four groups according to the type of bleaching protocol used. Color measurements were done by a spectrophotometer before bleaching, one day and one week after bleaching for all the experimental groups. Universal Testing Machine with cross head speed of $1 \mathrm{~mm} / \mathrm{min}$ was used for measuring microshear bond strength of the four investigated groups before and after bleaching. Data were analyzed statistically by: Duncan Multiple range test for means comparison and Paired t test for evaluating the effect of time and intervals on different parameters within each bleaching protocol. The significance level was set at $\mathrm{P} \leq 0.05$.
\end{abstract}

Results: The results showed different findings among the bleached groups when evaluated after 1 day and 7 days. It was found that non thermal atmospheric plasma has a stronger bleaching effect than LED light when used as an activating method. Furthermore, the light bleached group showed a significant decrease in the microshear bond strength values after bleaching. While, there was no statistically significant difference in microshear bond strength values of the other three groups.

Conclusion: The application of non thermal atmospheric pressure plasma is a promising method for intracoronal bleaching.

KEY WORDS: Intracoronal bleaching, non-thermal atmospheric pressure plasma, hydrogen peroxide.

\footnotetext{
* MSc. in Dental Materials Science, Faculty of Oral and Dental Medicine, Cairo University.

** Professor of Dental Materials Science, Faculty of Oral and Dental Medicine, Cairo University

*** Professor of Physics, Faculty of science, Al-Azhar University.
} 


\section{INTRODUCTION}

The increasing cultural appeal of beauty has reached great proportions. Good appearance is synonymous with personal and professional success. Dentistry assumes an important role in this search for esthetics. Tooth discoloration is becoming a greater concern as more emphasis is placed on esthetics. Tooth discoloration varies in etiology, appearance, location, severity, and affinity to tooth structure. It can be classified into extrinsic, intrinsic, and internalized discoloration according to its location and etiology. There are several ways to manage tooth discoloration, which include crowns, veneers, or tooth bleaching ${ }^{[1]}$.

Dental Bleaching has been received by the public as a more conservative and economical method of improving the appearance of the dentition. Hydrogen peroxide (HP) is the main active chemical component of most agents used in tooth bleaching therapies. HP can be used in its pure form or as the final product of the degradation of other bleaching substances, such as sodium perborate and carbamide peroxide (CP).HP diffuses into the tooth, dissociates to produce unstable free radicals which will attack organic pigmented molecules in the spaces between the inorganic salts in tooth enamel or dentin ${ }^{[2]}$. Although these agents are effective in lightening tooth color, their use has been associated with undesirable complications, including increased dentine permeability, changes in tooth structure, external root resorption, microleakage of restorations and reduced bond strength of composite resins.

Tooth bleaching can be performed externally, termed vital tooth bleaching, as well as intracoronally in root-filled teeth, called non-vital tooth bleaching. The bleaching of non-vital teeth is a minimally invasive intervention which, if performed correctly, bears only slight risks. Nevertheless, contradictory opinions and unanswered questions exist about this method. Recently, walking bleach, modified walking bleach, non-vital power bleaching (thermo/photocatalytic bleaching), and 'inside/outside bleaching have been introduced as different techniques for non vital bleaching ${ }^{[3]}$.

Many devices, such as halogen curing lights, light-emitting diodes (LEDs), diode lasers, argon lasers and plasma arc lamps have been used to speed the breakdown of hydrogen peroxide, resulting in faster whitening. They are used to catalyze the bleaching process by intensifying the oxi-reduction reaction and accelerating the release of hydroxyl $(\mathrm{OH}-)$ radicals. Their role have been unclear and in controversy. Thus, more safe, time saving and efficient methods for intracoronal bleaching therapy are required ${ }^{[4]}$.

Recently, non thermal plasmas have shown great potential as noble techniques to dental applications due to safety and multi-functional effects achieved by the abundant plasma components including charged particles, radiation, and reactive species. Non thermal atmospheric pressure plasma (NTAPP) is a specific type of plasma that is less than $104^{\circ} \mathrm{F}$ at the point of application. It is efficient in treating oral diseases because the construction of the plasma devices allows easy access to the oral cavity ${ }^{[5]}$. The current usage of plasma in dentistry is based on two approaches, i.e. surface treatment and direct application ${ }^{[6]}$.

NTAPP provides distinct advantages for tooth bleaching, particularly when used in conjunction with hydrogen peroxide. This has been attributed in part to the generation of copious amounts of reactive radicals in the plasma, particularly of reactive oxygen species, such as $\mathrm{HOO}$, and $\mathrm{OH}$. It is believed that the presence of per-hydroxyl anions $\left(\mathrm{HO}_{2}-\right)$ and .OH are particularly critical in tooth bleaching $^{[7]}$. In addition, it was found that a short treatment with plasma could change the chemical structure of the exposed collagen fibrils and increase the hydrophilicity of the dentin surface, which enhanced the bond strength at the adhesive-dentin interface ${ }^{[8]}$. Therefore, this study was designed to investigate the efficacy of intracoronal bleaching using non thermal atmospheric plasma in stained human teeth and its effect on pulp chamber dentin structure. 


\section{MATERIALS AND METHODS}

\section{Specimen preparation and bleaching procedure:}

A total of thirty eight single rooted premolars, extracted for orthodontic reasons, were selected to be used in this study. Then, teeth were stored in saline at room temperature until their use. Before experimental use, teeth were polished with AlphaPro ${ }^{\text {тм }}$ prophy medium grit paste using a polishing disposable cup mounted in a low speed hand piece to remove surface contaminates. The root of each tooth was embedded in self cured acrylic resin cubic blocks up to $1-2 \mathrm{~mm}$ below cementoenamel junction. Then, teeth were sectioned in half longitudinally in a mesio-distal direction with a double-faced diamond disc under water cooling yielding a total of 76 specimens. Specimens were immersed for 1-week period in a standardized coffee solution at room temperature $\left(27 \pm 2^{\circ} \mathrm{C}\right)$ in screw capped plastic containers ${ }^{[9]}$.

The sectioned teeth (76 specimens) were divided into four groups (19 each) according to the bleaching protocol (1-4). The bleaching treatment contact time was 30 min according to manufacturer's instructions for endodontically treated teeth.

In Group 1: specimens were treated with light activated bleaching agent (32\% hydrogen peroxide) and subjected to LED light. The bleaching agent with a standard volume of $0.5 \mathrm{~mL}$ for each specimen was applied on the dentin surface for 10 minutes. After 2 minutes of application, the gel was light activated by two 45-s applications using LED curing light. The gel was allowed to remain on the dentin surface for the rest of the 10 minutes. Then it was aspirated and the surfaces rinsed with $5 \mathrm{ml}$ distilled water. This procedure was performed 3 times giving a total application time of 30 minutes.

In Group 2: specimens were treated with chemically activated bleaching agent (32\% hydrogen peroxide) and subjected to plasma. A layer of 1-2 mm of bleaching gel was applied on the dentin surface. Then, the specimens were exposed to plasma from a plasma device at a distance of 10 $\mathrm{mm}$ away from the exit nozzle of the plasma jet.

In Group 3: specimens were treated with plasma only. The specimens were treated with plasma jet and saline solution( $(0.9 \%)$ for 10 minutes. The specimens were placed at a distance of $10 \mathrm{~mm}$ away from the exit nozzle of the plasma jet device. The saline solution was applied to the inner surface of the teeth to avoid dehydration. This procedure was performed for 30 minutes.

In Group 4: specimens were treated with chemically activated bleaching agent (32\% hydrogen peroxide) only.

\section{Plasma jet device:}

The plasma jet cell (figure 1) consisted of a glass tube with $1 \mathrm{~cm}$ diameter and $20 \mathrm{~cm}$ length. Two electrodes (inner and outer) were connected to a power supply to generate plasma inside the glass tube. The inner electrode was a copper rode of $0.5 \mathrm{~cm}$ diameter. The outer electrode is made of aluminum foil. A voltage of $6 \mathrm{kv}$ with frequency of $50 \mathrm{Hzwas}$ applied to the electrodes. The cell was fed by helium gas in atmospheric pressure with flow rate of $2 \mathrm{~L} / \mathrm{min}$. The consumed power in plasma jet was $47.5 \mathrm{~m}$ Watt.

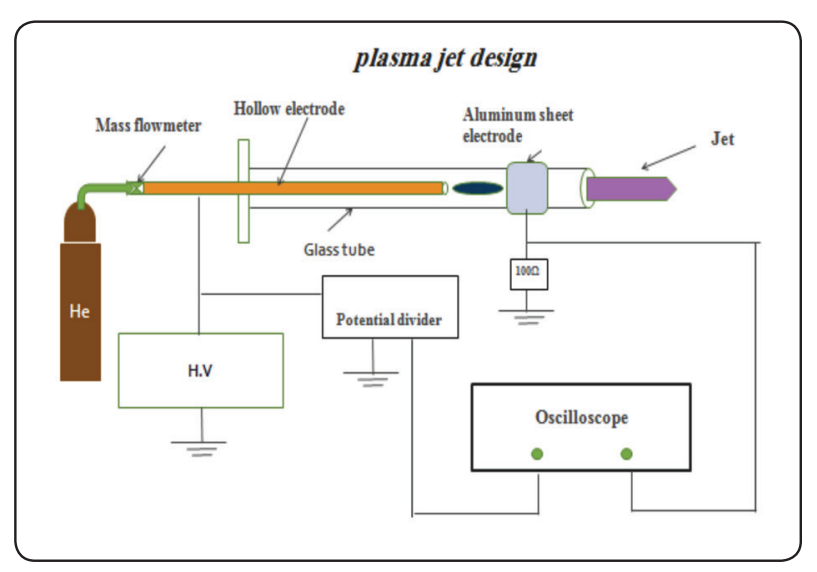

Fig. (1) A schematic diagram of the plasma device 


\section{Color measurement:}

Standard endodontic access cavities were prepared for fourteen teeth of the total number of teeth. Then, the prepared teeth were sectioned longitudinally in into two halves yielding a total of 28 specimens which were grouped into four groups according to the bleaching protocol (7 each). The color measurement was evaluated using a spectrophotometer (UV- VIS-NIRShimadzu3101 PC). The tested specimen was fixed to the hole of a specially fabricated holder with a width of $4 \mathrm{~mm}$.

First a baseline correction over the required wave length range was performed to record $100 \%$ line flatness. Then, color measurements were evaluated for each specimen in the same way as the baseline. The reflectance of each specimen was represented by a graph drawn by the computer of the spectrophotometer. They were evaluated at different time periods namely: Before bleaching, one day after bleaching and one week after bleaching.

Values were expressed according to the Commission Internationale de L'Eclairage Lab (CIELAB) Color System. The CIELAB system uses three parameters, $L^{*}, a^{*}$, and $b^{*}$, where $L^{*}$ indicates the brightness, and $a^{*}$ and $b^{*}$ describe the amount of green-red and blue-yellow, respectively, in the color space of the tooth. The differences in the values of $\mathrm{L}^{*}, \mathrm{a} *$, and $\mathrm{b} *$ in each group were measured. The values of the color changes $(\Delta E)$ of the tested specimen were calculated according to the following formula ${ }^{[10]}$ :

$$
\Delta \mathrm{E}=\sqrt{(\Delta \mathrm{L} *) 2+(\Delta \mathrm{a} *) 2+(\Delta \mathrm{b} *) 2}
$$

To relate the amount of color change $\left(\Delta \mathrm{E}^{*}\right)$ recorded by the spectrophotometer to a clinical environment, the data were converted to National Bureau of Standards units (NBS units) through the equation, NBS units $=\Delta \mathrm{E}^{*} \times 0.92$, where critical remarks of color differences expressed in terms of NBS units (table 1).
TABLE (1) Critical remarks of color change according to the National Bureau of Standards ${ }^{[1]}$

\begin{tabular}{|l|c|}
\hline Critical remarks of color differences & NBS unit \\
\hline Trace: Extremely slight change & $0.0-0.5$ \\
\hline Slight: Slight change & $0.5-1.5$ \\
\hline Noticeable: Perceivable change & $1.5-3.0$ \\
\hline Appreciable: Marked change & $3.0-6.0$ \\
\hline Much: Extremely marked change & $6.0-12.0$ \\
\hline Very much: Change to other color & 12.0 or more \\
\hline
\end{tabular}

\section{Microshear bond strength $(\mu \mathrm{SBS})$ test:}

A total of 48 specimens (prepared from 24 teeth) were used for the microshear bond strength testing with control group $(n=24)$ and bleached group $(n=24)$. Specimens were grouped into four groups according to the bleaching protocol.

\section{Preparation of specimens for testing:}

All surfaces of the specimens (control and bleached) were finished using 320 and 400 grit SiC paper for 1 minute with a water coolant to obtain a smooth flat surface with a standardized smear layer. A disposable applicator brush was used to rub the adhesive (Single Bond Universal) on the tooth surface for 20 seconds, then direct gentle air streaming for 5 seconds was done till complete evaporation of the solvent then light cured for 20 seconds. Two rubber micro tubes of $0.9 \mathrm{~mm}$ diameter were placed as a mold for the flowable composite on the flat dentin surface on each tooth half. Then, flowable composite was injected inside the tubes, covered by a celluloid strip and light cured for 20 seconds. The specimens were stored for 24 hours in in distilled water for $\mu \mathrm{SBS}$ testing. The specimens were tested by Universal Testing Machine (LLOYD $5 \mathrm{~K}$ ) with cross head speed of $1 \mathrm{~mm} / \mathrm{min}$ using a loop wire. Micro shear bond strength results were gained by dividing the debonding forces on the surface area automatically using Nexygen software. 


\section{Statistical analysis}

Statistical analysis was carried out using SPSS program (Statistical Package for the Social Sciences). One way analysis of variance (SPSS, analyze, compare means, one way ANOVA) was used to test the effect of bleaching protocols on color. Duncan Post-Hoc Multiple Comparisons (PostHoc) at $\mathrm{p} \leq 0.05$ was used for means comparison. Paired t test (dependent-samples t-test) was used for evaluating the effect of time and intervals on different parameters within each bleaching protocol.

\section{RESULTS}

\section{Color change analysis}

The results of the color changes in the four tested groups at each time period are given in table 2 and presented graphically in figure 2 . Initially, the results from zero time (before bleaching) to $1^{\text {st }}$ day and from zero time to $7^{\text {th }}$ day revealed that there was a statistically significant difference between the four groups. The plasma combined with chemical bleached group showed the statistically significant highest mean value $(\Delta \mathrm{E}=3.136 \pm 0.244)$ while the plasma bleached group which showed the statistically significant lowest mean value $(\Delta \mathrm{E}=0.969 \pm 0.176)$.

However, the results from $1^{\text {st }}$ day to $7^{\text {th }}$ day revealed that; the plasma combined with chemical bleached group showed the statistically significant highest mean value $(\Delta \mathrm{E}=0.460 \pm 0.198)$. Furthermore, there was no statistically significant difference between the chemical bleached group and plasma bleached group; both showed the significantly lowest mean value $(\Delta \mathrm{E}=0.266 \pm 0.102$ and $0.246 \pm 0.118$ respectively).

TABLE (2) Mean, standard deviation (SD) and NBS values for $(\Delta \mathrm{E})$ changes in the four investigated groups at each time period

\begin{tabular}{|c|c|c|c|c|c|c|c|c|c|c|c|c|}
\hline \multirow{2}{*}{$\begin{array}{lll}\begin{array}{l}\text { Bleaching } \\
\text { protocol }\end{array} & \text { Time }\end{array}$} & \multicolumn{4}{|c|}{ Zero time to $1^{\text {st }}$ day } & \multicolumn{4}{|c|}{$1^{\text {st }}$ day to $7^{\text {th }}$ day } & \multicolumn{4}{|c|}{ Zero time to $7^{\text {th }}$ day } \\
\hline & $\begin{array}{c}\text { Mean } \\
(\Delta \mathrm{E})\end{array}$ & $\mathrm{SD}$ & $\mathrm{dt}$ & $\begin{array}{l}\text { NBS } \\
\text { unit }\end{array}$ & $\begin{array}{l}\text { Mean } \\
(\Delta \mathrm{E})\end{array}$ & $\mathrm{SD}$ & $\mathrm{dt}$ & $\begin{array}{l}\text { NBS } \\
\text { unit }\end{array}$ & $\begin{array}{l}\text { Mean } \\
(\Delta \mathrm{E})\end{array}$ & SD & $\mathrm{dt}$ & $\begin{array}{l}\text { NBS } \\
\text { unit }\end{array}$ \\
\hline Light bleached & 2.048 & 0.184 & $\mathrm{~b}$ & 1.884 & 0.343 & 0.203 & $a b$ & 0.315 & 1.784 & 0.111 & $\mathrm{~b}$ & 1.641 \\
\hline $\begin{array}{l}\text { Plasma combined with } \\
\text { chemical bleached }\end{array}$ & 3.136 & 0.244 & $\mathrm{a}$ & 2.885 & 0.460 & 0.198 & $\mathrm{a}$ & 0.423 & 2.768 & 0.123 & $\mathrm{a}$ & 2.546 \\
\hline Plasma bleached & 0.969 & 0.176 & $\mathrm{~d}$ & 0.891 & 0.246 & 0.118 & b & 0.226 & 0.867 & 0.094 & d & 0.797 \\
\hline Chemical bleached & 1.454 & 0.112 & $\mathrm{c}$ & 1.337 & 0.266 & 0.102 & $\mathrm{~b}$ & 0.244 & 1.288 & 0.066 & $\mathrm{c}$ & 1.184 \\
\hline
\end{tabular}

dt= Duncan's Multiple Range Test for the effect of bleaching protocol.

Means with the same letter within each column are not significantly different at $p=0.05$.

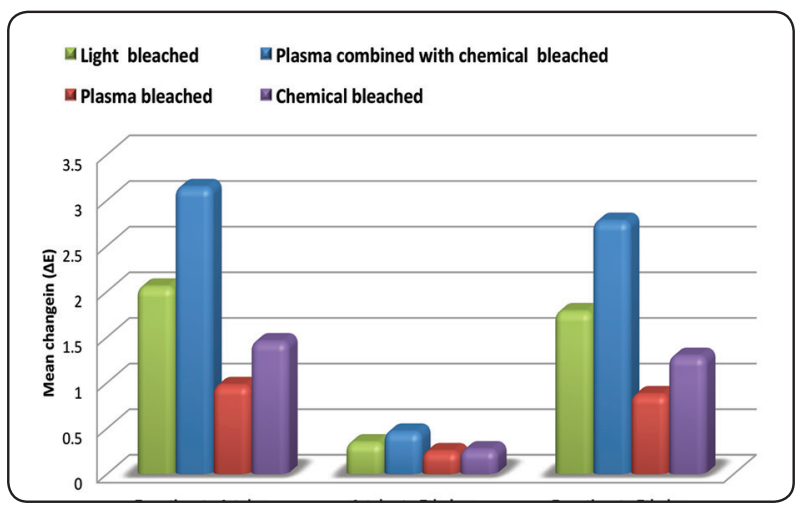

Fig. (2) Mean $(\Delta \mathrm{E})$ changes of the four investigated groups at each time period

\section{Microshear bond strength:}

\section{Microshear bond strength (MPa) values before and after bleaching within each group:}

The results of mean microshear bond strength before and after bleaching in each group are given in table 3 and presented graphically in figure 3 . In the light bleached group; the results showed a significant decrease in the microshear bond strength values after bleaching. While, in the other three groups; there was no statistically significant difference in microshear bond strength values. 
TABLE (3) Mean values of microshear bond strength(MPa) before and after bleaching within each investigated group

\begin{tabular}{|c|c|c|c|c|c|c|c|c|}
\hline \multirow[b]{2}{*}{ Bleaching protocol } & \multicolumn{2}{|c|}{ Before } & \multicolumn{2}{|c|}{ After } & \multirow{2}{*}{$\begin{array}{c}\text { Mean } \\
\text { Diff. }\end{array}$} & \multirow{2}{*}{$\begin{array}{l}\text { S.E. } \\
\text { Diff. }\end{array}$} & \multirow[b]{2}{*}{ t value } & \multirow[b]{2}{*}{$\mathrm{p}$} \\
\hline & $\begin{array}{l}\text { Mean } \\
(\mathrm{MPa})\end{array}$ & S.D. & $\begin{array}{l}\text { Mean } \\
(\mathrm{MPa})\end{array}$ & S.D. & & & & \\
\hline Light bleached & 14.50 & 4.834 & 8.92 & 4.582 & -5.583 & 1.983 & -2.816 & $0.017 *$ \\
\hline Plasma combined with chemical bleached & 12.42 & 5.760 & 10.33 & 3.420 & -2.083 & 2.141 & -0.973 & $0.351 \mathrm{NS}$ \\
\hline Plasma bleached & 13.00 & 2.486 & 10.58 & 2.999 & -2.417 & 1.190 & -2.031 & $0.067 \mathrm{NS}$ \\
\hline Chemical bleached & 11.75 & 2.832 & 13.50 & 4.834 & 1.750 & 1.875 & 0.933 & $0.371 \mathrm{NS}$ \\
\hline
\end{tabular}

NS $=$ Non significant $p>0.05, *=$ Significant at $p$

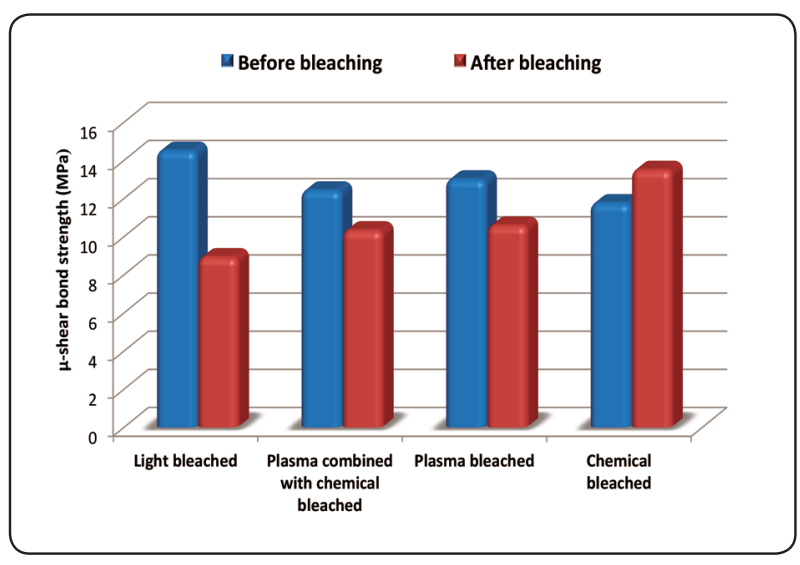

Fig. (3) Mean values of microshear bond strength(MPa) before and after bleaching within each investigated group

\section{DISCUSSION}

Many techniques have been used for dental bleaching, especially for non-vital teeth. Success of dental bleaching is related to the ability of the bleaching material to penetrate through dentinal tubules. The deeper the penetration, the more the pigment that causes chromatic alteration can be reversed by the oxidation reaction, converting dark molecules into carbon dioxide and water ${ }^{[12,13]}$. Since the introduction of in-office bleaching treatments, the use of curing lights (including halogen curing lights, plasma arches, LED and lasers) has been recommended to accelerate the action of the bleaching ge ${ }^{[14]}$. However, the efficacy of light sources used in tooth bleaching is doubtful. Serious concerns regarding the safety of this technique, in particular the risk of producing external cervical root resorption, changes in tooth structure and reduced bond strength of composite restoration have rendered this technique questionable. This have propelled researchers to investigate other whitening alternatives $^{[15]}$.

Utilizing plasma to enhance tooth bleaching and remove surface proteins is in its infancy, but significant progress is being made. The potential for a chemical-free, non-thermal whitening procedure is desirable as an adjunct or alternative to existing techniques. The challenge of reducing chair time and minimizing the reapplication of bleaching gels is also critical in order to limit current side effects. NTAPP enhanced bleaching, with or without added gels or solutions, may someday be the gold standard in tooth bleaching ${ }^{[16]}$.

A few recent invitro studies ${ }^{[17-20]}$ suggest that the use of NTAPP improves the whitening capabilities without causing thermal damage or altering surface morphology. But most of these studies were done extracoronally. Accordingly, the present study was directed to evaluate the efficacy of intracoronal bleaching using non thermal atmospheric pressure plasma in stained human teeth and its effect pulp chamber dentin structure. 
Two types of bleaching systems were used in this study namely; chemical activated and light activated $32 \%$ hydrogen peroxide bleaching agents. Both types were recommended for intracoronal bleaching of endodontically treated non-vital teeth. The light activated bleaching agent contains active chlorophyll which absorbs light and converts it into oxygen and energy.

Intact premolars were selected in this study due to their availability as they were extracted for orthodontic reasons. Some studies ${ }^{[11,21]}$ concluded that coffee was the most chromogenic agent in comparison with other staining substances, such as tea and cola drinks. Therefore, a coffee solution was used in this study following the method proposed by Suleiman et al ${ }^{[9]}$ for standardization of the tooth shade. To perform this internal tooth discoloration, the teeth were sectioned midway longitudinally. This enabled the chromate to diffuse into the teeth from the dentino-pulpal wall (i.e. from inside) mimicking the internal tooth discoloration. In addition, standard endodontic access cavities were prepared for fourteen teeth (used for color change assessment) for simulating the clinical procedure ${ }^{[22]}$. Thus the bleaching agents reached the enamel and surface dentin by diffusion via the dentinal tubules.

In the present study, non-thermal atmospheric pressure plasma device was assembled and formed into a jet shape with compact size that can be transformed later to a handheld and conveniently operated device to be used in dental clinics. The plasma temperature of the jet can be easily controlled between room temperature and human body temperature by simply adjusting plasma parameters $^{[23]}$.

\section{Color change:}

Several factors such as lightening conditions, translucency, opacity, light scattering and human variables may influence the overall perception of tooth color. To eliminate the potential of subjective errors in color assessment, a reflection spectrophotometer was used in this study for color measurement. Compared with observations by the human eye, or conventional techniques, it was found that spectrophotometers offered a $33 \%$ increase in accuracy and a more objective match in $93.3 \%$ of cases $^{[24]}$.

Regarding the efficacy of bleaching, the results (table 2, figure 2) revealed that there was a statistically significant difference between the four groups from zero time to $1^{\text {st }}$ day and zero time to $7^{\text {th }}$ day. The plasma combined with chemical bleached group showed the statistically significant highest mean value $(\Delta \mathrm{E}=3.136$ and 2.768 respectively). This demonstrates that the NTAPP has a stronger bleaching effect than LED light when used as an activating method. The NTAPP produces large amounts of energetic ions, charged particles, and free radicals, these might interact with the HP, thereby synergistically enhancing the bleaching effect.

Furthermore, the results showed that intracoronal tooth bleaching NTAPP associated with $32 \% \mathrm{HP}$ was more effective than treatment with $32 \% \mathrm{HP}$ or plasma only. These results were in agreement with Park et al ${ }^{[25]}$.and Claiborne et al. ${ }^{[26]}$. This might be due to the increased production of $\mathrm{OH}$, which is crucial in tooth bleaching, significantly over that produced by HP alone.

The present study also investigated the efficiency of tooth bleaching by a non thermal plasma jet (PJ) as a standalone tool without addition of a bleaching agent. However, a saline solution $(0.9 \% \mathrm{NaCl})$ is added to keep the tooth surface constantly moist. The effectiveness of the PJ in tooth whitening is most likely due to the production of ROS (reactive oxygen species) at the plasma-tooth interface, which is similar to what occurs at the whitening gel-tooth interface in the traditional process ${ }^{[17]}$. In addition, the $\mathrm{PJ}$ might react with $\mathrm{NaCl}$ in the saline solution to produce chlorine-based ions and radicals. However, since the concentration of $\mathrm{NaCl}$ in the saline solution is very low $(0.9 \%)$, only trace amounts of the chlorine-based ions and radicals 
was expected to be produced so that they were not expected to contribute significantly to the whitening effect.

Regarding the color change from $1^{\text {st }}$ day to $7^{\text {th }}$ day; the results (table 2, figure 2) revealed that a slight color rebound might have occurred in the four bleaching groups. Tooth dehydration after a bleaching procedure may contribute to the overall lightening effect ${ }^{[27]}$. This may result in a false assessment of the color change. Bleach products have a component that is used as a vehicle for active peroxide substances called glycerin. Glycerin absorbs water on its own leading the water molecules to migrate from the inside of the tooth through enamel and dentin and make contact with the hydrogen peroxide gel, leaving the tooth with low concentration of water; therefore, dehydration may occur ${ }^{[28]}$.

The ability of the human eye to appreciate color differences may change from individual to individual. $\Delta \mathrm{E}^{*}$ values have been used to evaluate the "perceptibility" of color differences. However, it is noteworthy that the criteria for perceptibility adopted by each author were different. To counter such differences and disagreements in the criteria used, the NBS rating system is frequently used to determine the degree of color difference, since it offers absolute criteria by which $\Delta \mathrm{E}^{*}$ values can be converted to remarks with clinical significance. Sepulveda-Navarro et al. ${ }^{[29]}$ used NBS (National Bureau of Standards) through the equation NBS units $=\Delta E \times 0.92$. Critical remarks of NBS units are 0.00.5 (trace), 0.5-1.5 (slight), 1.5-3.0 (noticeable), 3.0-6.0 (appreciable), 6.0-12.0 (much) and \pm 12.0 (very much).

In the present study, corresponding NBS units were calculated to assess the color differences caused by the different bleaching protocols. The NBS values for both the plasma combined with chemical bleached group and the light bleached group at different time periods (zero time to $1^{\text {st }}$ day and zero time to $7^{\text {th }}$ day) were greater than 1.5 , meaning that color change was noticeable (perceivable). On the other hand the chemical bleached group and plasma bleached group at the same time periods were in the range of $0.5-1.5$, meaning that there was a slight change that can be visible to a trained operator. In addition, the color change values (NBS) from $1^{\text {st }}$ day to $7^{\text {th }}$ day for all groups were below 0.5 , meaning than color change was a traceable change.

\section{Microshear bond strength:}

Several studies suggest that bleaching treatments alter bond strengths in vital and non-vital teeth ${ }^{[30}$, 31]. This could be explained by the presence of $\mathrm{OH}-$ radicals after the break down of hydrogen peroxide which can act on intertubular and peritubular dentin breaking the polypeptide chains and degrading components of connective tissue, thereby, attacking the organic component of dentin. Additionally, the bond strength might be reduced due to the presence of residual oxygen. Oxygen release can interfere in the penetration of resin into dentinal tubules, as well as inhibition of resin polymerization.

In the light bleached group; the results (table 3 , figure 3) showed a significant decrease in the microshear bond strength values after bleaching. This is probably due to the fact that LED light might have produced a significant temperature rise on dentin and, consequently, generates thermal adverse effects that could affect dentin bond strength. However, in the other three groups; there was no statistically significant difference in microshear bond strength values. These results were in agreement with Homewood et al. ${ }^{[32]}$ and Amara et al. ${ }^{[33]}$ whose results showed that the use of in-office bleaching didn't cause an alteration in bonding strength.

In the present study, after the bleaching treatment, the specimens were polished to obtain a flat dentin surface. This procedure may have altered the dentin surface and removed residues of hydrogen peroxide. Accordingly, there was no change in the bond strength values after the bleaching procedure of the chemical bleached group. In addition, 
there was no decrease in bond strength values in the plasma bleached groups. Previous studies ${ }^{[8,34]}$ showed the prospect of utilizing non-thermal plasma for dentin surface treatment to improve the interface bonding of composite restorations. Plasma treatment increase the hydrophilicity and carbonyl groups of the dentin surface which allow better penetration of adhesive into dental collagen fibrils and enhance the bond strength at the adhesive-dentin interface. There are some limitations of the present study that must be considered, as in most invitro studies, the oral environment is impossible to be fully simulated. So, further invivo investigations are needed to identify the efficacy of intracoronal bleaching using non thermal atmospheric pressure plasma.

\section{CONCLUSIONS}

Within the limits of this study, the following was concluded:

1. Treatment with non thermal atmospheric pressure plasma associated with $32 \%$ HP is a promising method for intracoronal bleaching.

2. The light activated bleaching produced a dramatic decrease in the microshear bond strength values.

3. Progress needs to be made concerning parameters of the plasma jet to improve its efficacy and performance in the oral cavity.

\section{REFERENCES}

1. Plotino G, Buono L, Grande NM, Pameijer CH and Somma F. Non vital tooth bleaching: a review of the literature and clinical procedures. J Endod. 2008; 34: 394-407.

2. Alqahtani M. Tooth-bleaching procedures and their controversial effects: A literature review. Saudi Dent J. 2014; 26(2):33-46.

3. Zimmerli B. Jeger F. and Lussi A. Bleaching of Non vital Teeth. A Clinically Relevant Literature Review. Schweiz Monatsschr Zahnmed. 2010; 120:306-320.

4. Nam SH, Lee HW, Cho SH, Lee JK, Jeon YC and Kim GC. High-efficiency tooth bleaching using non thermal atmospheric pressure plasma with low concentration of hydrogen peroxide. J Appl Oral Sci. 2013; 21(3):265-270.

5. Kim GC, Lee HW, ByunJH., Chung J., Jeon YC and Lee JK. Dental Applications of Low-Temperature Non thermal Plasmas. Plasma Process Polym. 2013;10:199-206.

6. Cha S and Park YS. Plasma in dentistry. Clinical Plasma Medicine. 2014;2(1): 4-10.

7. Lee HW, Kim GJ, Kim JM, Park JK, Lee JK and Kim GC. Tooth bleaching with non thermal atmospheric pressure plasma. J Endod. 2009; 35:587-91.

8. Ritts AC, Li H, Yu Q, Xu C, Yao X, Hong L and Wang Y. Dentin surface treatment using a non-thermal argon plasma brush for interfacial bonding improvement in composite restoration. Eur J Oral Sci. 2010;118(5):510-516.

9. Meireles SS, Fontes ST, Coimbra LA, Della Bona A and Demarco FF. Effectiveness of different carbamide peroxide concentrations used for tooth bleaching: an in vitro study. J Appl Oral Sci. 2012; 20(2): 186-191.

10. Canay S and Cehreli MC. The effect of current bleaching agents on the color of light polymerized composites: an invitro study. J Prosthet Dent. 2003;89:474-8.

11. Koksal T and Dikbas I. Color stability of different denture teeth materials against various staining agents. Dent Mater J. 2008;27:139-144.

12. Carrasco LD, Guerisoli DMZ, Rocha MJA, Pecora JD and Froner IC. Efficacy of intracoronal bleaching techniques with different light activation sources. IntEndod J.2007;40:204-208.

13. Ferreira R, Vieira T, Martins BK and Garcia RN. Effects of catalase, $2 \%$ chlorhexidine gel and $1 \%$ sodium hypochlorite on the microtensile bond strength of teeth bleached with 35\% hydrogen peroxide. RSBO. 2011;8(3):266-270.

14. Lima DA, Aguiar FH, Liporoni PC, Munin E, Ambrosano GM and Lovadino JR. In vitro evaluation of the effectiveness of bleaching agents activated by different light sources. J Prosthodont. 2009; 18:249-54.

15. Fearon J. Tooth whitening: concepts and controversies. Int Dent SA. 2009;11(2):24-38.

16. McCombs GB.PlasmaDent: Breakthrough Technology for Dental Hygiene and Dentistry. The Richmond Institute for Continuing Dental Education(ADA CERP). 2013.

17. Pan J, Sun P, Tian Y, Zhou H, Wu H, Bai N, Liu F, Zhu W, Zhang J, Becker K H, and Fang J. A novel method of tooth whitening using cold plasma micro jet driven by direct current in atmospheric-pressure air. IEEE Trans. Plasma Sci.2010;38(11): 3143-3151. 
18. Wang J, Yang X, Sun K, Sun P, Pan J, Zhu W, Becker k H, Zhang J and Fang J. Tooth Enamel Evaluation After Tooth Bleaching With Hydrogen Peroxide Assisted by a DC Non thermal Atmospheric-Pressure Plasma Jet. IEEE Trans. Plasma Sci. 2012;40(9): 2157-2162.

19. Lee HW, Nam SH, Mohamed A-AH, Kim GC and Lee JK. Atmospheric pressure plasma jet composed of three electrodes: Application to tooth bleaching. Plasma Process Polym. 2010;7:274-280.

20. Kim MS, Koo IG, Choi MY, Jung JC, Eldali F, Lee JK and Collins GJ. Correlated electrical and optical studies of hybrid argon gas-water plasmas and their application to tooth whitening. Plasma Process Polym. 2012;9(3):339-345.

21. Ertas E, Guler AU, Yucel AC, Koprulu H and Guler E. Color stability of resin composites after immersion in different drinks. Dent Mater J. 2006;25:371-376.

22. Da Sà PM, Jeronymo RDI, Yui KCK, de Silva EG, Huhtala MFRL, Torres CRG and Gomes APM. Effect of Calcium on $\mathrm{pH}$ Changes of the External Medium after Intracoronal Bleaching. J Contemp Dent Pract. 2011:12(3):158-163.

23. Chen M, Zhang Y, Sky Driver M, Caruso AN, Yu Q and Wang Y. Surface modification of several dental substrates by non-thermal, atmospheric plasma brush. Dent Mater: Off PublAcad Dent Mater. 2013;29:871-80.

24. Akin M, Dilber E, Basciftci FA and Ozturk B. Effect of microabrasion on teeth color. Turkish J Orthod. 2013;26:80-84.

25. Park JK, Nam SH, Kwon HC, Mohamed AAH, Lee JK and Kim GC. Feasibility of non thermal atmospheric pressure plasma for intracoronal bleaching. IntEndod J. 2011;44(2):170-5.

26. Claiborne D, McCombs G, Lemaster M, Akman MA and Laroussi M. Low-temperature atmospheric pressure plasma enhanced tooth whitening: the next-generation technology. Int. J Dent Hygiene.2014;12(2):108-114.

27. Kugel $G$ and Ferreira S. The art and science of tooth whitening. J Mass Dent Soc. 2005;53:34-37.

28. Natalia RK. Effect Of dehydration on in-office bleaching color changes. MS thesis. University of Iowa, USA. 2012.

29. Sepulveda-Navarro WF, Arana-Correa BE, Borges CP, Jorge JH, Urban VM and Campanha NH. Color stability of resins and nylon as denture base material in beverages. J Prosthod. 2011;20(8):632-638.

30. Shinohara MS, Peris AR, Pimenta LA and Ambrosano GM. Shear Bond Strength Evaluation of Composite Resin on Enamel and Dentin after Non vital Bleaching. J Esthet Restor Dent. 2005;17:22-29.

31. Souza-Gabriel AE, Vitussi LOC, Milani C, Alfredo E, Messias DCF and Silva-Sousa YTC. Effect of bleaching protocols with $38 \%$ hydrogen peroxide and postbleaching times on dentin bond strength. Braz Dent J. 2011;22(4):317-21.

32. Homewood C, Tyas $\mathrm{M}$ and Woods $\mathrm{M}$. Bonding to previously bleached teeth. Aust Orthod J. 2001; 17(1): 27-34.

33. Amaral C, Jorge A, Veloso K, Erhardt M, Arias V and Rodrigues JA. The effect of in-office in combination with intracoronal bleaching on enamel and dentin bond strength and dentin morphology. J Contemp Dent Pract. 2008;9(5):17-24.

34. Valverde GB, Coelho PG, Janal MN, Lorenzoni FC, Carvalho RM, Thompson VP, Weltemann KD and Silva NR. Surface characterization and bonding of Y-TZP following non-thermal plasma treatment. J Dent. 2013;41:51-9. 